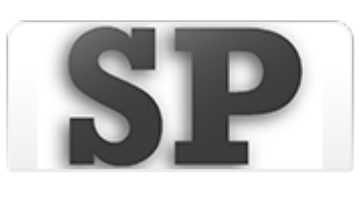

Sociedades precapitalistas

ISSN: 2250-5121

publicaciones@fahce.unlp.edu.ar

Universidad Nacional de La Plata

Argentina

\title{
Reseña del libro Dell'Elicine, Eleonora, y Martin, Céline (eds.). Framing power in Visigothic Society. Discourses, Devices and Artifacts. Amsterdam: Amsterdam University Press, 2020. (224 pp.)
}

Pérez, Mariel

Reseña del libro Dell'Elicine, Eleonora, y Martin, Céline (eds.). Framing power in Visigothic Society. Discourses, Devices and Artifacts. Amsterdam: Amsterdam University Press, 2020. (224 pp.)

Sociedades precapitalistas, núm. 10, 2020

Universidad Nacional de La Plata, Argentina

DOI: https://doi.org/10.24215/22505121e051 
Reseña del libro Dell'Elicine, Eleonora, y Martin, Céline (eds.). Framing power in Visigothic Society. Discourses, Devices and Artifacts. Amsterdam: Amsterdam University Press, 2020. (224 pp.)

Mariel Pérez

DOI: https://doi.org/10.24215/22505121e051

Instituto de Historia Antigua y Medieval "José Luis

Romero". Facultad de Filosofía y Letras. Universidad

de Buenos Aires. CONICET (Consejo Nacional de

Investigaciones Cientificas y Técnicas), Argentina

marielperez@conicet.gov.ar

Recepción: 30 Abril 2020

Aprobación: 04 Mayo 2020

En los últimos años los estudios visigodos han cobrado un gran ímpetu, lo que se reflejó no sólo en la multiplicación de los trabajos de investigación y la publicación de nuevas ediciones documentales, sino también en la aparición de una diversidad de intereses y perspectivas, la introducción de marcos teóricos novedosos y el intenso desarrollo de una arqueología renovada en sus métodos que permitió iluminar procesos y estructuras sociales que las fuentes escritas relegaban a una relativa oscuridad. Es en este marco que encuentra su lugar Framing Power in Visigothic Society, que tiene además el paradójico mérito de ser, en vista de este enorme desarrollo historiográfico, la primera obra colectiva dedicada al mundo visigodo tras la publicación de las compilaciones de Alberto Ferreiro (1999) y Peter Heather (1999) hace ya más de veinte años.

El presente volumen, editado por Eleonora Dell'Elicine (Universidad Nacional de General Sarmiento, Argentina) y Céline Martin (Université Bordeaux-Montaigne, Francia), recoge siete trabajos que, en su conjunto, examinan las prácticas y dispositivos de poder desplegados en la sociedad visigoda a través de aproximaciones metodológicas diversas como la filología, la arqueología, la historia jurídica, la diplomacia o la numismática. Desde esta multiplicidad de prismas se reflexiona sobre la construcción de una serie de mecanismos de ejercicio del poder, su funcionamiento y su papel en las formas de articulación social, al tiempo que se aportan elementos significativos a la discusión sobre ciertos problemas específicos y se contribuye, de forma más amplia, a la actualización de las interpretaciones y perspectivas de análisis sobre la sociedad visigoda.

Los estudios de Jacques Elfassi y Dolores Castro abordan el papel del texto escrito y el recurso a elementos de autoridad en la construcción de dispositivos de poder, poniendo el foco de análisis en la obra de Isidoro de Sevilla. Elfassi realiza un minucioso análisis de la presencia de San Agustín en la obra de Isidoro, haciendo correcciones a la lista de obras de Agustín que, hasta el momento, se consideraban conocidas por Isidoro. A su vez, aporta algunos elementos a la reflexión sobre el recurso a Agustín por parte del obispo hispalense, que se desplegaba en el plano de la doctrina teológica, la exégesis bíblica y la definición de ciertos conceptos. El uso de Agustín por Isidoro sería multifacético, incorporando ciertas modificaciones; esto no significaba negar la autoridad de Agustín sino actualizar su obra como forma de ser más fiel a su pensamiento. Por su parte, Dolores Castro analiza el papel de la exégesis bíblica en la construcción del poder episcopal, examinando los métodos de lectura, interpretación y enseñanza de los textos bíblicos desarrollados en la obra de Isidoro. La autora muestra que, para el obispo de Sevilla, la búsqueda de la verdad divina sólo era posible en espacios específicos de estudio y perfección espiritual, a la vez que requería de una serie de procedimientos específicos 
y de un sujeto experto capaz de descubrir los significados ocultos del texto bíblico. De esta forma, el mensaje divino sólo podía ser descifrado en el marco de la Iglesia a través de sus Doctores, en particular, sus obispos. La exégesis bíblica se convertía así en un dispositivo de enorme importancia en la jerarquización del acceso a la palabra de Dios y en la definición de un grupo social cuya mediación era indispensable en su transmisión, favoreciendo la consolidación de la autoridad episcopal dentro de la sociedad visigoda y reforzando -en un contexto de reciente conversión del arrianismo a la doctrina nicena- la unidad de la identidad religiosa.

Carlos Tejerizo y Eleonora Dell'Elicine ponen el foco de atención en las sociedades locales, sus formas de articulación, jerarquización y cohesión. El trabajo de Tejerizo ofrece un recorrido por la historiografía sobre el campesinado visigodo a la luz del desarrollo de la arqueología, enfatizando la contribución que en los últimos años realizó esta disciplina a la revisión de ciertos tópicos historiográficos. En este sentido, destaca como puntos centrales el reconocimiento del surgimiento de las comunidades campesinas en la temprana Edad Media -frente a las interpretaciones clásicas de la naissance du village en los siglos X-XI, en el marco de la revolución feudal (Fossier, 1982)-, la temprana presencia de redes de aldeas estables y organizadas, la comprensión de la complejidad de las formas de identidad en las sociedades rurales, que trascendían el elemento étnico, y la identificación de las desigualdades internas que atravesaban las sociedades campesinas. Esto último se sitúa en un marco historiográfico fuertemente marcado por la impronta de la obra de Chris Wickham (2005) y su elaboración de la noción de modo de producción campesino para conceptualizar las sociedades rurales temprano-medievales. Desde esta perspectiva, estas sociedades eran relativamente igualitarias, aunque no excluían la presencia de ciertas formas de diferenciación social. La arqueología sobre el campesinado visigodo contribuye a fortalecer esta concepción, mostrando, a partir de la evidencia material, la existencia de diversos factores de diferenciación social y la presencia de jerarquías dentro de las comunidades rurales.

En este marco puede inscribirse el trabajo de Eleonora Dell'Elicine, que a través de un análisis de los cultos paganos aporta elementos de gran interés para comprender la complejidad de las sociedades locales en el reino visigodo. La autora sitúa la diversidad de prácticas idolátricas dentro de los contextos locales: en tanto el objeto/dios o su residencia se concentraban en un lugar específico, el culto implicaba una relación focalizada con el territorio, una organización del espacio en torno a un referente particular. Los sujetos involucrados en estas prácticas también apuntan a un contexto local: esclavos e ingenui. Los ritos idolátricos actuaban como dispositivos de articulación social, creando o reforzando determinados agrupamientos sociales; a su vez, la participación en los mismos ponía en juego elementos de prestigio y poder dentro de esos grupos. En este sentido, estos cultos actuaban como instrumento de construcción de lazos sociales y relaciones de poder a escala local. Al mismo tiempo, la erradicación de estos cultos, en tanto articuladores de jerarquías locales, constituían un mecanismo de organización del territorio por parte de los poderes centrales.

Céline Martin, Margarita Vallejo y Ruth Pliego ponen el foco de atención en los dispositivos de poder desplegados por la monarquía visigoda. El trabajo de Martin analiza la reforma del sistema legal llevada a cabo por Ervigio, buscando comprender el abandono de la pena de muerte para los delitos políticos y religiosos y su sustitución por el exilio. Conjugando el estudio de la legislación con el de la práctica jurídica, Martin concluye que la eliminación de la pena de muerte se ajustaba a realidad de la práctica jurídica, en la que la pena capital ya había sido de hecho sustituida por el exilio. En este sentido, la reforma de Ervigio se orientaba a ajustar la ley y la práctica, lo que contribuía a fortalecer la credibilidad del sistema jurídico y, por tanto, de la monarquía. A su vez, los cambios en la propia práctica jurídica responden, para la autora, a la influencia del pensamiento cristiano, que dejaba lugar a la reforma del culpable. Al plasmar esto en la legislación, Erivigio contribuía pues a la imagen un rey visigodo cristiano y piadoso. Por su parte, Vallejo examina las relaciones diplomáticas entre el reino visigodo y el imperio bizantino durante el reinado de Sisebuto, poniendo de manifiesto que estos intercambios ponían en juego no sólo la consecución de objetivos prácticos sino también otros aspectos más sutiles como el mutuo reconocimiento político y la construcción de la imagen del monarca. Finalmente, Pliego nos ofrece un panorama minucioso y actualizado sobre el estado actual de los conocimientos sobre la 
moneda visigoda, mostrando a su vez cómo la moneda constituía un importante dispositivo de poder de la monarquía, articulando el territorio del reino y afirmando la imagen regia.

Desde una perspectiva de conjunto, Framing Power in Visigothic Society presenta varios méritos que le otorgan un lugar significativo en la historiografía sobre el mundo visigodo. Por un lado, aborda la problemática del ejercicio del poder desde una pluralidad de aproximaciones y recursos metodológicos, sin perder un sentido de conjunto a través de sus ejes articuladores. A su vez, ofrece al lector perspectivas historiográficas actualizadas sobre temas centrales en el estudio del período, como la arqueología de las sociedades rurales, el análisis filológico de los textos o el estado del conocimiento sobre la numismática visigoda. Finalmente, contribuye con aportes novedosos para comprender los dispositivos y prácticas de poder en la sociedad visigoda, al tiempo que proporciona una serie de reflexiones para el abordaje de otros problemas como el papel de los elementos étnicos, la circulación monetaria o las características de la sociedad campesina. En este sentido, el libro constituye un valioso aporte para los estudiosos del mundo visigodo, así como también para quienes se dedican al estudio de otras sociedades temprano-medievales europeas.

\section{REFERENCIAS}

Ferreiro, A. (ed). (1999). The Visigoths: studies in culture and society. Leiden-Boston: Brill.

Fossier, R. (1982). Enfance de l'Europe (Xe-XIIe siècle). Aspects économiques et sociaux. I : L'homme et son espace. Paris: Presses universitaires de France.

Heather, P. (ed.). (1999). The Visigoths from the Migration Period to the Seventh Century: an ethnographic perspective. Woodbridge: Boydell.

Wickham, Ch. (2005). Framing the Early Middle Ages: Europe and the Mediterranean, 400-800. Oxford: Oxford University Press. 